\title{
SCORM Cloud for an Advanced Sequencing of Learning Objects on LMS Moodle Platform
}

\author{
Miguel Sánchez-Brito ${ }^{1}$, José Ruiz-Ascencio ${ }^{1}$, and Carlos Felipe García-Hernández ${ }^{2}$ \\ ${ }^{1}$ Centro Nacional de Investigación y Desarrollo Tecnológico (CENIDET), Mexico \\ ${ }^{2}$ Instituto de Investigaciones Eléctricas (IIE), Morelos, Mexico \\ \{miguelsb,josera\}@cenidet.edu.mx, cfgarcia@iiie.org.mx
}

\begin{abstract}
In this research work, the results obtained from the SCORM Cloud module verification in a learning platform (Learning Management System) Moodle 1.9.19, are presented. For this module verification, learning objects based on standard SCORM 2004 Fourth Edition were used, with sequencing according to ADL proposed template 10 and whose sequencing process was developed in a previous, published, research work. Due to scarce information, coupling a Learning Management System (Moodle 1.9.19 in this case) with SCORM Cloud becomes complicated, this paper presents a full description of how to couple SCORM Cloud into a Learning Management System.
\end{abstract}

Keywords: SCORM Cloud, Moodle, ADL template 10, sequencing, learning object, on-line course automation, intelligent tutoring, learning objectives.

\section{Introduction}

Learning Management System (LMS) has provided a new opportunity of academic advancement for people who want to continue learning and do not have enough time to follow a course in an academic institution with a fixed schedule.

Through these learning platforms the users can enter to conduct their academic activities without time restrictions (unless otherwise decided) and only need a computer with internet access. Within the platform, users with role of "Teacher" or "Administrator" have the ability to add a wide range of resources and activities that contribute to a student's academic background.

Located within the activities, highlighted activities called "SCORM activities" are learning objects developed using an authoring tool in order to be submitted and evaluated by the LMS. The way these activities are made is very important, since it should be visually appealing and interactive for capturing user attention, however it is of equal or greater importance the way in which the material is presented to the student. These activities have sub activities, but there is currently no method to set the sequencing of them to be presented 
to the student appropriately (based on their interactions in a previous activity). Subactivities sequencing is done using a software called Reload Editor. With the Reload Editor, rules precondition, post-condition and output conditions, in order to present these subactivities in an organized manner are configured. There are two ways to perform the sequencing of several Shareable Content Object(SCO), the first is done using identifiers learning objectives (LO) of resources are integrated into the authoring tool to Mapping Local Objectives and the second is by establishing objectives with the Reload Editor (ADL Objectives).

Currently, learning objects that are displayed in an LMS must meet the requirements of the Shareable Content Object Reference Model (SCORM) standard, the most current version of the 2004 Fourth Edition, if an advanced sequencing for the material is required.

SCORM Cloud [2] provides the possibility to reap the benefits of an advanced sequencing based on (local and ADL) objectives of the 2004 fourth edition of SCORM, in platforms that are not able to support that version. Due to scarce information, coupling an LMS (Moodle 1.9.19 in this case) with SCORM Cloud becomes complicated and that is why this is the goal of this research work. The objective is to use the Moodle LMS platform to verify the LO based on the 2004 fourth edition of SCORM, correctly reporting information from the interaction of a student in that activity.

The flexibility provided by the 2004 fourth edition of the SCORM standard for sequencing the LO to be presented to students is unfortunately wasted because most platforms (including Moodle [3]), support only version 1.2 of the standard. Version 1.2 allows only a simple sequencing, that is, within a LO with more than one activity (Multi SCORM package or activity), the student may advance to the next sub-activity or SCO (Shared Content Object) only when the current one is completed. All previous SCO are freely available for consultation, even when the post-exam is reached.

This paper is organized as follow: Section 2 provides related works about SCO sequencing and an application of pedagogical tools to an on-line course for e-learning. Section 3 presents the details of the configuration used to couple SCORM Cloud module within the LMS Moodle. Section 4 covers the verification of SCORM Cloud. Section 5 presents the results of this verification. Finally Section 6 and 7 cover the future work and conclusion for this research.

\section{Related Work}

In [4] authors explain in detail the way to achieve SCORM activities configuration, involving sub-activities or several SCO (as named in SCORM standard, being learning objects containing teaching materials), following the guidelines proposed by ADL with Template 10 and Educative Model 3, and using Reload Editor software. Two forms of achieving sub-activities sequencing of an SCORM activity, are described, applying learning objectives mapping for each activity (from Author Tool) and setting ADL objectives with Reload in order to evaluate them, using shared global objectives and sub-activities 
cumulative (roll out). In [5] authors explain an application of pedagogical tools to an online course for e-learning, including an example of a course specification showing an activity, an example of an script for an activity, and a course development model.

\section{Configuring the SCORM Cloud module in Moodle}

The SCORM Cloud module used for the configuration tests accommodates LMS Moodle platforms versions 1.9.x. The new module is installed on the server in the directory ../htdocs/Moodle/mod. Figure 1 shows the location of the SCORM Cloud module Moodle files.

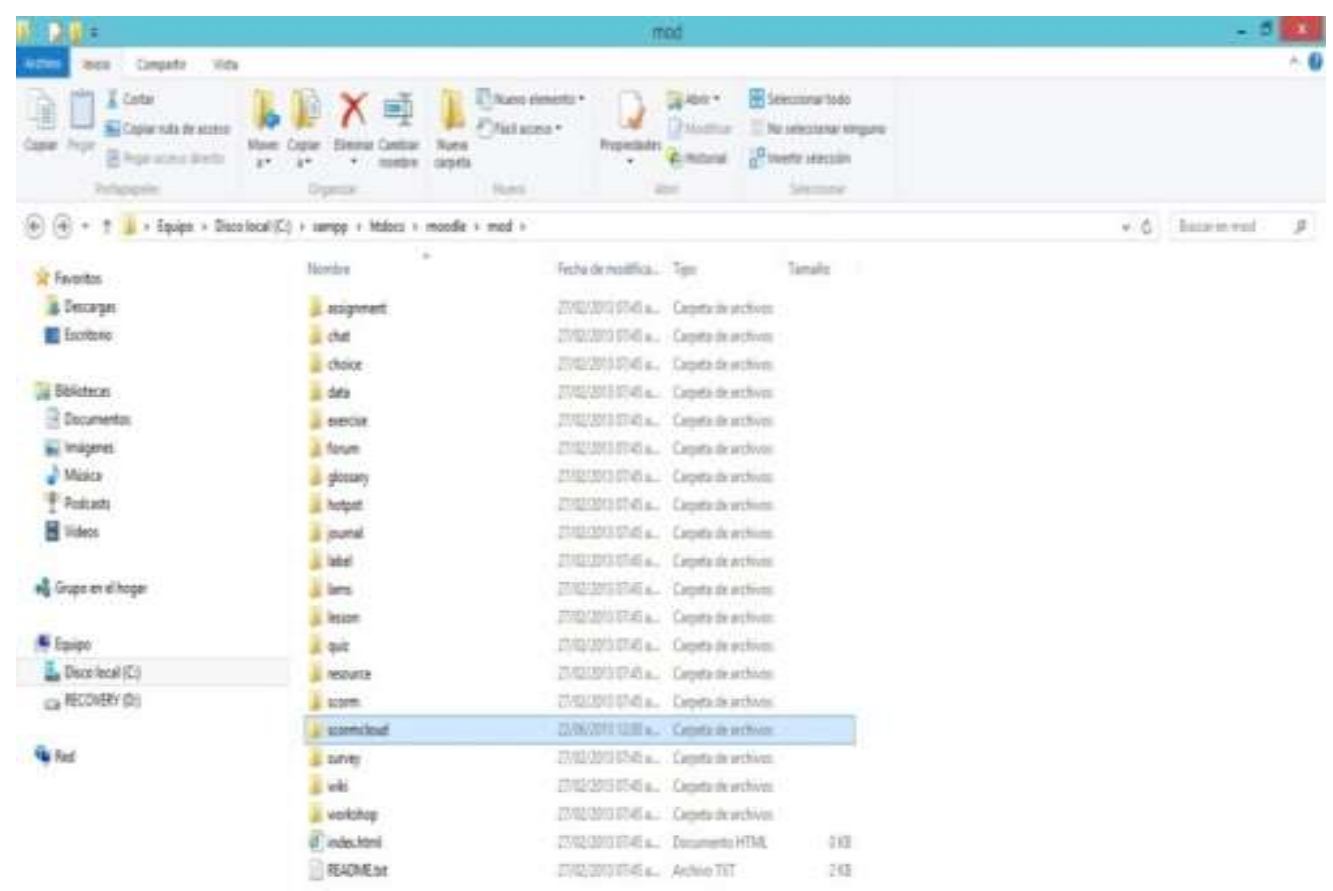

Fig.1. SCORM Cloud module location within Moodle files.

After configuring the new module, it is available in the LMS "Add activity..." menu of the option "Notifications" in the LMS administration menu. Figure 2 identifies the "SCORM Cloud" module in the menu mentioned above. Then, LO preloaded from the LMS "Administration" menu "Files" option was selected in the configuration form of SCORM Cloud activity. 


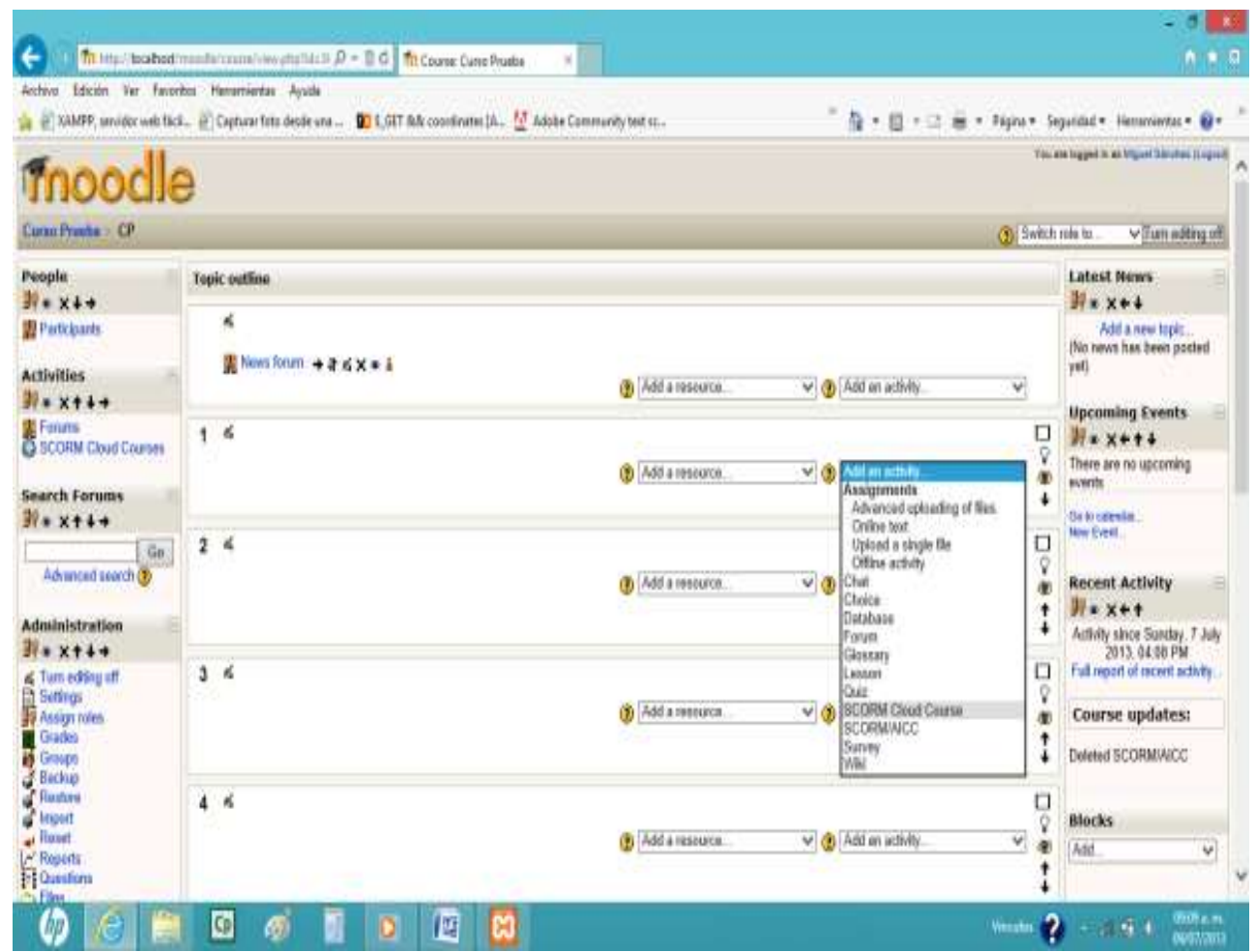

Fig.2. SCORM Cloud module within the "Add an activity..." menu in Moodle.

\section{Verification of SCORM Cloud}

Verification process of this new module required a LO sequenced with the capabilities of SCORM 2004 Fourth Edition, using the Reload Editor [1]. The example LO was sequenced according to the guidelines of the ADL template 10 (sequencing configuration of the LO was detailed in [4]). Figure 3 shows the behavior with which an LO was sequenced according to this template.

The depiction of Figure 3 is detailed including learning objectives in [4], and is shown in Figure 4.

\section{$5 \quad$ Results}

LO sequenced behavior was verified in a LMS Moodle platform version 1.9.19 installed locally. Visualization of the LO is performed in an additional window that is enabled to 


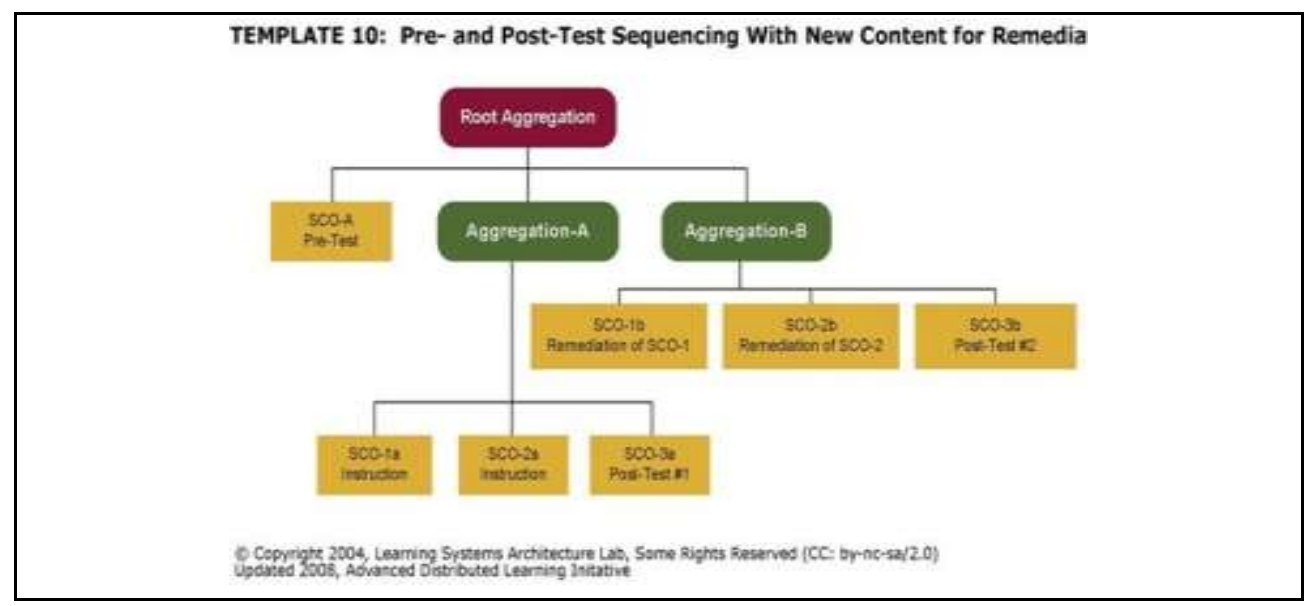

Fig.3. ADL Template 10 [1].

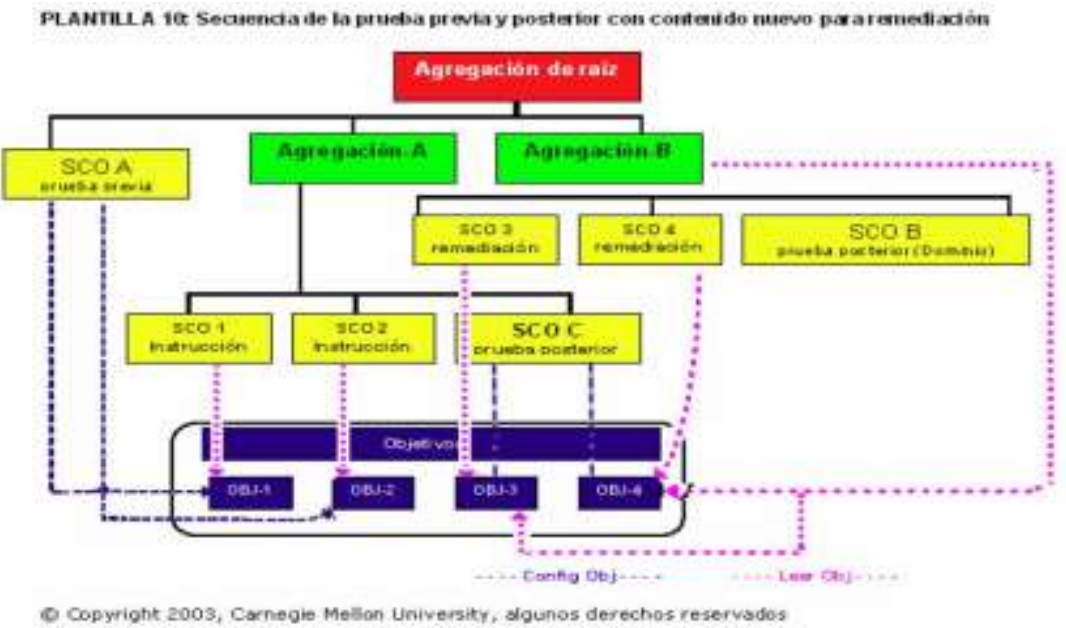

Fig.4. Template 10 based on learning objectives.

display this activity. Figure 5 shows the message launched when an LO is started in SCORM Cloud.

The SCORM Cloud module has a configuration given by RUSTICI [2] (the developers of the SCORM Cloud module). In Figure 6 the configuration mentioned above is shown and also the proper functioning of the LO is depicted, as in first instance it only shows the ordinary material, while remediation material remains hidden. 


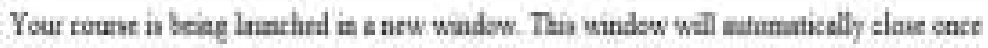
Iowexit the wan:

Fig.5. Launching a new window for the SCORM Cloud module.

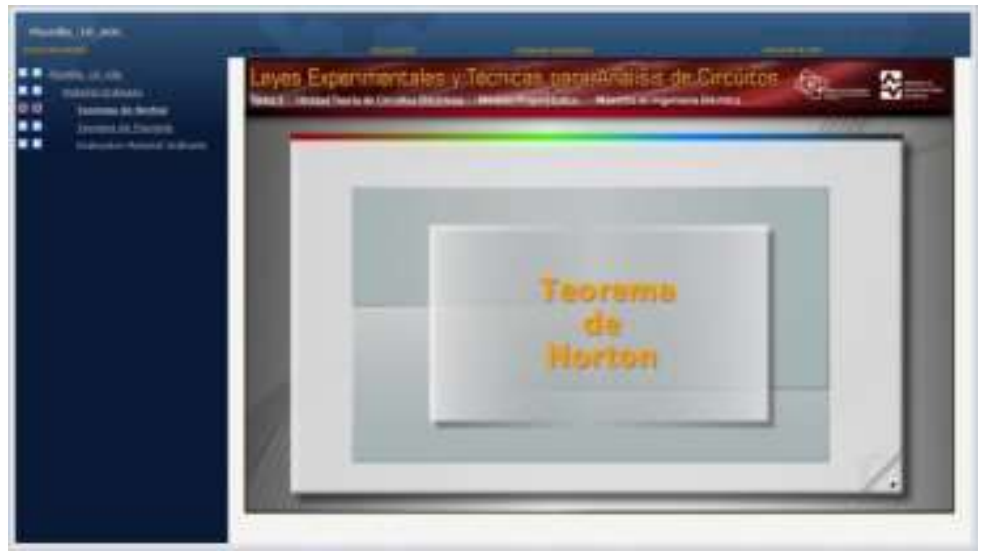

Fig.6. Ordinary material presented in the SCORM Cloud module.

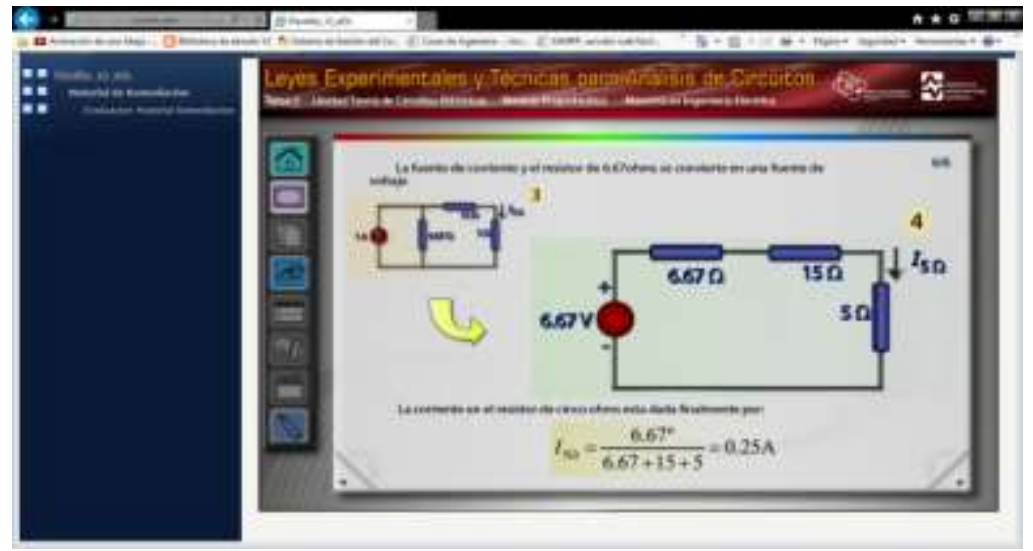

Fig.7. Review of remediation material.

Once the interaction in the Post Exam is completed and depending on the grade obtained in this activity, the student can exit the course or have the option to take the remediation material. This behavior is specified in ADL template 10. Figure 7 shows the interaction of 
the student in the remediation material. Once the material has been passed (either ordinary material or remediation), student results are exported to the LMS gradebook.

Figure 8 shows the results of the interaction in LMS corresponding to testing a student in the SCORM Cloud module. An important detail to note is that the results are not exported to the LMS gradebook, but remain in the analysis module, that is why the student's grade has to be written manually in the LMS gradebook.

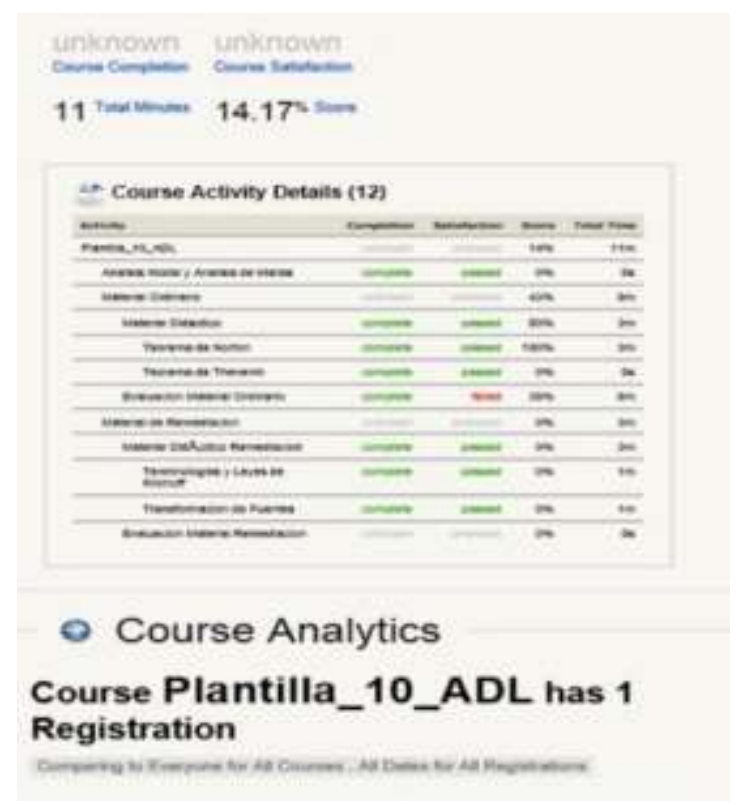

Fig.8. Results from the interaction of a testing student in SCORM Cloud module.

\section{Conclusion}

In this research work, advanced sequencing of learning objects based on the SCORM 2004 Fourth Edition standard for e-learning, was covered in full, since it is now possible to sequence learning objects in an advanced way and display them in an LMS which is lagged behind this standard. This brings us one step closer to automating online courses delivered through an LMS, where the advanced sequencing is the last step of the intelligent tutoring. Due to scarce information, coupling an LMS (Moodle 1.9.19 in this case) with SCORM Cloud becomes complicated, this paper presents a full description of how to couple SCORM Cloud into an LMS.

As future work, the recording of an LO grade in the LMS gradebook is proposed. Moreover, checking SCORM and LMS Moodle websites constantly is recommended, in case an important new feature or update appears. 
Miguel Sánchez Brito, José Ruíz Ascencio, and Carlos Felipe García-Hernández

\section{References}

1. Advanced Distributed Learning Network, http://www.adlnet.org (2014)

2. Rustici Software, http://www.scorm.com (2014)

3. Moodle, http://www.moodle.org (2014)

4. García-Hernández, C. F., Sánchez-Brito, M., Jiménez-Fraustro, F. F.: Configuración de la Plantilla 10 y Modelo Educativo 3 de ADL: Secuenciamiento con Remediación. X Congreso Internacional sobre Innovación y Desarrollo Tecnológico CIINDET 2013, No. 620, Cuernavaca, Morelos, México, pp. 1-7 (2013)

5. Anbar, A. A., Al-Shishtawy, A. M., Al-Shandawely, M., Mostafa, T. A., Bolbol, A., Hammad, A., Sunoallah, S., Everett, J., Özgüven, K.: Applying Pedagogical Concepts in Online Course Development: Experiences from the Mediterranean Virtual University, pp. 1-11 (2005) 